\title{
Research Status and Working Mechanism of the Concrete Expanded- Plates Pile under Horizontal Load
}

\author{
Yongmei Qian ${ }^{1,2^{\star}}$, Yuhui Zhang ${ }^{1}$, Jie Wang ${ }^{1}$, Ruozhu Wang ${ }^{1}$, \\ 1 Jilin Jianzhu University, Changchun, 130118 \\ 2 Jilin Structure Seismic Technology Innovation Center,Changchun,130118 \\ Corresponding author: 654675316@qq.com
}

\begin{abstract}
Keywords: the concrete expanded-plates pile (the CEP pile), horizontal load, research status, working mechanism
\end{abstract}

Abstract. The concrete expanded-plate pile (the CEP pile) has special construction of the pile body, which makes the pile have higher bearing capacity by addition of bearing extruded-expanded-plate. By research it is shown that there are many factors to affect the bearing capacity of the single pile of the CEP pile, so the situation is very complex. Compared with the ordinary concrete straight hole pile, the CEP pile has good horizontal bearing performance. In this paper, the research status of the CEP pile under horizontal load is summarized, and the load transfer law of pile body and the soil surrounding the pile, the working mechanism of concrete expanded-plates pile under horizontal load is described, the need for further research on the failure mechanism and bearing capacity is put forward. The paper provides references for the design and application of this type of pile.

\section{Introduction}

As a new type of the concrete expanded-plates pile, in the engineering field, has expressed its special advantage. Because of the existence of the concrete expanded-plates, the compressive bearing capacity of single pile is greatly improved, at the same time it has a good uplift resistance performance. For this pile, national and foreign scholars have done a lot of research, the research on the vertical bearing capacity is basically perfect. In recent years, with the increasing of national economy in China, the continuous development of urban construction, development and utilization of underground space, different functions and types of construction projects are increasing, the buildings, structures, bridges, and underground space engineering in civil engineering are subjected to horizontal loads, even the situation of horizontal dynamic load is gradually increased, such as: earthquake, wind, offshore platform, high voltage power grid and supporting of deep foundation pit, and so on.

How to solve the overturning resistance bearing capacity of pile foundation, under the action of horizontal load in the engineering structure, has become one of the problems that are often faced with and need to be solved urgently. The overturning resistance of ordinary concrete pile with same cross-section is very limited, as a new type of variable cross-section pile, the concrete expandedplates pile, of course, becomes the most effective way to solve the problem of overturning resistance, which is applied increasingly widespread in practical engineering. Because of the existence of the expanded-plates, a good level of performance resisting the horizontal force is shown, and the length of the pile can be reduced effectively, which realizes its social and economic benefits.

Although in recent years, some progress has been made in the research of the concrete expandedplates pile at home and abroad, but, which is still in the initial stage of exploration, the research achievements of the concrete expanded-plates pile are more concentrated in the study of compression and uplift bearing capacity, the failure mechanism and bearing capacity under horizontal load are relatively lacking, so far, a preliminary study on the stress state of extrudedexpanded multi-plates pile is carried out in a small amount of literature, including numerical simulation and model test research in laboratory. The relevant parameters of the calculation and design for the horizontal bearing capacity of the concrete expanded-plates pile are not perfect, 
therefore, there is a certain gap in the study on the bearing capacity of the concrete expanded-plates pile under horizontal load.

\section{Analysis of research status}

The rapid development and application of the concrete expanded-plates pile from which is produced, it is almost perfect that the research on the vertical compression and uplift bearing capacity of the concrete expanded-plates pile, at present, the research on the horizontal bearing capacity of the concrete expanded-plates pile has become a new research focus in the field of engineering.

Through Adina simulation of the finite element software, Professor Wei Long analyzes the load bearing capacity of the extruded-expanded multi-plates pile set in the different position, advances the buried depth of bearing plate is an important factor affecting the action of bearing plate, and put forward the diameter, the angle of the slope of the bearing plate are also the factors that affect the bearing plate resistant the horizontal load[1], among them, buried depth of the bearing plate has the maximum affection for the bearing capacity.

Lu Xilei and others, through the model test indoor, have complete the comparison and analysis of the law of load transfer and the interaction mechanism of pile and soil, when the supporting plate is arranged at the different position of the pile, such as the upper part or the lower part of the pile. It is put forward that the supporting plate set on the upper part of the pile body is more reasonable for resisting horizontal load, simultaneously, the location of supporting plate set should be lower under the scope of the soil may rise, a point of soil is selected in the middle of the pile,under the same horizontal force, of which the soil pressure is smaller when the supporting plate is set at the upper part of pile [2].

The research of Gao Xiaojuan is based on the analytical answers of ordinary pile under horizontal load, the calculation method of horizontal bearing capacity of extruded-expanded multi-plates pile is put forward. At the same time, by finite element simulation, the qualitative analysis is done that the position, number, spacing, diameter of the bearing plate, and the length, diameter of pile, top constraint conditions of pile, soil properties, and so on, for the affection on the horizontal bearing performance of extruded-expanded multi-plates pile[3].

Wang Haitian, etc., based on the elastic foundation reaction method, combined with deformation curve of pile, by using the finite difference method, put forward a calculation method on displacement and internal force of extruded-expanded multi-plates pile[4]. Professor Lu Chengyuan analyzes the stress and deformation characteristics of the pile group extruded-expanded multi-plates pile when the pile spacing is $2 \mathrm{D}, 2.5 \mathrm{D}, 3 \mathrm{D}$ ( $\mathrm{D}$ is the diameter of the bearing plate), by research model of pile groups including two pile, model test indoor. With the increase of pile spacing, the bending moment and deflection of the pile are all reduced, while the increase of pile top displacement, the extruded-extended plate express the better effect for counterpoising bending moment of pile, the bending moment of the pile is obviously reduced at the location under the plate, but, the bigger pile spacing, effect of group pile is weak. When the pile spacing is more than 3 times the diameter of the pile, the effect of group pile can not be considered [5].

Professor Zhao Liping, based on the model of group piles with $2 \times 4$ rows, has studied the force characteristics of piles under horizontal force. In his paper, the change of bending moment of the pile is analyzed, it is proposed that the effect of pile group and effect of side pile have the affection on the bending moment of pile. Again, when the distance between piles is two times the diameter of the bearing plate, group pile effect is more obvious, the stress superposition phenomenon between the pile and the soil exists at the location of $0 \sim 2 \mathrm{~m}$ up to the soil surface. At the aspects of proportion distributed of horizontal loads, the front row pile is greater than the back row pile for affording the horizontal load, and then the pile is before the front row pile for separation of the pile and soil[6]. 


\section{Working mechanism of extended-plates pile under horizontal load}

Frigid pile and elastic pile. Under the action of horizontal load, according to the relative stiffness of pile and soil, pile is divided into rigid pile and elastic pile[2]. General situation, when the pile diameter is larger, pile length is shorter, and soil properties surrounding the pile is bad, the concrete expanding pile is considered as a rigid pile, conversely, as an elastic piles. Under the action of horizontal force, rigid rotation around one point of the pile will occur, the parabolic deformation from pile top to pile end develops for elastic pile, the curvature of curve of upper the bearing plate is larger than under it, as shown in Figure 1.

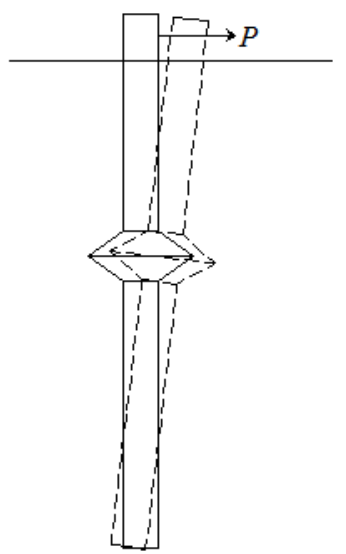

(a) Rigid pile

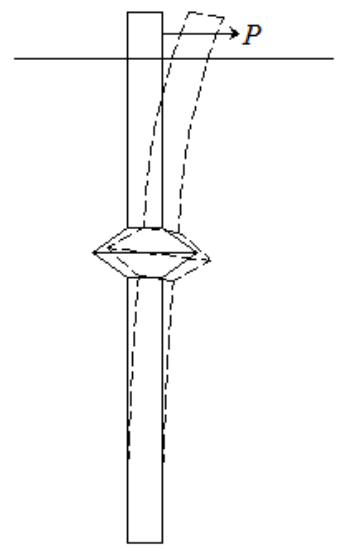

(b) Elastic pile

Figure 1 Schematic diagram of the deformation of pile under horizontal load

The horizontal bearing capacity of the concrete expanded-plate pile is mainly determined by the size and shape of the pile, strength and stiffness of the pile and the properties of the soil around the pile, and shear strength of soil[7]. The horizontal bearing capacity of the rigid pile is mainly determined by the strength of the soil around the pile, the horizontal bearing capacity of the elastic pile is determined by the bending resistance stiffness of the pile and the strength of the soil around the pile.

Working mechanism of concrete expanding pile under horizontal load. Compared with the ordinary concrete pile with straight hole, because of the existence of the expanded plate, the contact area between the pile and the soil is increased, when the lateral displacement of the pile is generated under horizontal force, the expanded plate will produce a certain rotating angle as well, the compression of the soil upper or under the plate will produce resistance, that is the bending moment resistance, to counterpoise the bending moment of pile, so the horizontal bearing capacity of the pile is greatly improved. In this paper, taking the rigid pile as an example, as shown in Figure 2, it is discussed that the load transfer law of the concrete expanded-plate pile under horizontal load.

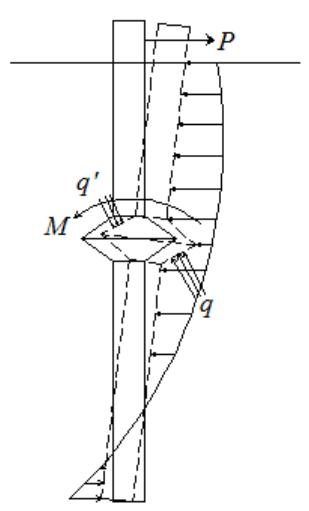

Figure 2 Diagram of bearing mechanism of supporting pile under horizontal load 
When the horizontal displacement at pile top is very small, the horizontal force is transmitted to the upper layer soil by the pile body, the upper layer soil is in the behavior of elastic compression, which will produce the horizontal resistance for resisting the horizontal load. At this time, because the lateral displacement of the concrete extended-plate pile is very small, the expanded plate has little rotation, the soil around the plate does not produce a significant bending moment resistance .

With the increasing gradually of the load, the extended-plate develops larger rotation following the pile, the upper layer soil enters the plastic deformation state, the deformation area of the soil is extended downstairs along the pile, load is transferred to the lower part of the soil. At this time, soil mass on both sides of the plate are respectively generated by the force majeure $\mathrm{q}$ and $\mathrm{q} /$, respectively, the bending moment resistance $\mathrm{M}$ is formed. The bending moment resistance of soil counterpoises greatly the bending moment of pile, so the bending moment of the pile under the plate becomes smaller, so as to improve the level of bearing capacity, effectively resist lateral displacement. Simultaneously, on the side direction of the horizontal force loaded, outside the upper layer of soil compressed, there will be a slight uplift of the soil body.

It shows, when the displacement of pile top is very smaller, the expanded-plate does little produce effect. Only the displacement of pile top is large enough to expanded-plate to produce a certain rotation, the soil around the plate will resist bending moment, the advantage of the plate can be played. In practical engineering, if the displacement of the pile top is strictly limited, expandedplate's advantages can not be fully played.

\section{Conclusion}

Because the special structure of concrete expanded-plate pile, it is extended of the contact area of the pile and soil, which make the ability to resist horizontal loads to be much greater than that of ordinary concrete. In practical engineering the structure of affording horizontal force is found everywhere, the concrete expanded-plate pile is an effective method to solve this problem. Although for the horizontal bearing capacity of the concrete expanded-plate pile, the domestic scholars do some research, but which is limited in finite element numerical simulation and model test indoor, the research results also give a rough qualitative analysis. Therefore, the research on concrete expanded-plate pile is far from enough, further research on the horizontal bearing capacity of the concrete expanded-plate pile should be made in the following aspects:

At present, it is compared and analyzed that the data get through strain gauge embedded in the pile body and the pressure box set in the soil, which can not really make the changes of pile and the soil around the pile to be observed in the process of the soil up to failure. To solve this problem, it can be applied that the test model with the half cross-section pile from the invention of project group, in order to deep study of load transfer law and displacement change of pile body and soil around pile, analyze the failure mechanism of concrete expanded-plate piles under horizontal load.

Because there are some limitations for the model test in the laboratory, the large scale test should be combined, the parameters of the concrete expended-plate pile under the horizontal is collected and analyzed. The exact range of different influence factors should be given so as to provide reliable theoretical basis for the design of concrete expanded-plate pile, and the calculation model of the horizontal bearing capacity of the concrete expanded-plate pile to be improved.

\section{Acknowledgment}

This work is financially supported by National Natural Science Foundation of China (51278224).

\section{References}

[1] Wei Long, Bin Chen.Numerical simulation analysis of the horizontal load resistance of squeezed branch pile[J].Shanxi Architecture, 2008,34(2):9-10 
[2]Xilei Lu, Chenyuan Lu, Hongkai Lu.Study on the horizontal bearing capacity of the pile with different set of disc[J].journal of zhejiang university of technology, 2011,39 (1) :51-56

[3]Xiaojuan Gao, Fengjun Liu, Yaohui Li, etc..Discussion on some problems of horizontal bearing capacity of pile[J].engineering mechanics, 2009,26(7):97-104

[4] Haitian Wang, Anhuan Wang, Tie Zhang.Analysis of load bearing performance of squeezed branch pile under horizontal load[J].Jiangsu Construction, 2014,5(1):76-78

[5] Chengyuan $\mathrm{Lu}$, Jianhua Yan.Experimental study on horizontal bearing behavior of pile group with different pile spacing[J].building technology, 2013,44(4):373-377

[6] Linping Zhao, Li Xiang, Chen Lu, etc.Force characteristic analysis of pile group under horizontal load[J].Industrial buildings ,2009,39(10):52-56

[7] Haijun Lin, Liangfeng Xia, Zhen Liu .Discussion on some problems of horizontal bearing capacity of pile[J].Zhejiang Construction, 2009,26(5):26-29 